\title{
Clinical Utility of Melatonin in Fibromyalgia Diagnosis
}

\author{
Ali M. El-Sayed Yousef ${ }^{a}$. Sherry K. Abd El-Rahman ${ }^{b}$ Hatem A. EL-Mezayen $^{c}$ Eman R. \\ Amer (Ph D) ${ }^{d}$. Shimaa Sabry ${ }^{e}$ and Camelia A. Abdel-Malak ${ }^{f}$ \\ ${ }^{a}$ Departments of Internal Medicine, ${ }^{b}$ Rheumatology and Rehabilitation, Benha Teaching Hospital, Benha, \\ Egypt. \\ ${ }^{\mathrm{c}}$ Department of Chemistry, Biochemistry Division, Faculty of Science, Helwan University, Helwan, Egypt. \\ ${ }^{d}$ Department of clinical pathology, Benha Teaching Hospital, Benha, Egypt. \\ eDepartment of Chemistry, Biochemistry Division, Faculty of Science, Damietta University, Damietta, Egypt. \\ 'Department of Chemistry, Biochemistry Division, Faculty of Science, Damietta University, Damietta, Egypt.
}

\section{ABSTRACT:}

Fibromyalgia syndrome (FMS) is a chronic disease with an unknown etiology, which is characterized by reduced pain threshold (hyperallgesia) \& pain with normally innocuous stimuli (allodynia).This diffuse pain is often disease associated with wide range of other symptoms including fatigue, sleep disturbance, stiffness\& more.FMS often occur concomitantly with other rheumatologic disease such as rheumatoid arthritis(RA), systemic lupus erthymatosus(SLE).

The pineal hormone melatonin (MT) exerts a variety of effects on the immune system. MT activates immune cells and enhances inflammatory cytokine and nitric oxide production.

\section{METHODS:}

We were studied 75 subjects, 55 of subjects were FMS patients defined by the American Colleague of Rheumatology (ACR 2010) criteria. Patients' mean age was $32.5 \pm 13.9$ years. They were classified into two groups: Group I of 25 primary FMS patients. Group II of $\mathbf{3 0}$ secondary FMS patients with other rheumatologic disease such as RA, SLE. Twenty age and sex matched healthy individuals were included in the study as a control group.

\section{RESULTS:}

Mean Melatonin titers were significantly reduced $(p<0.0001)$ in primary FMs patients compared to the controls $(\underline{21.32 v s}$. $30.9 \mathrm{pg} / \mathrm{ml}$ ), but they were significantly elevated $(\mathrm{p}<0.0001)$ in secondary FMS compared to controls $(138.1 \mathrm{vs} .30 .9 \mathrm{pg} / \mathrm{ml})$. Our data imposed that, in 1ry FMS there were negative correlations of MT titers with tender points $\left(r=-0.848^{* *}, p<0.0001\right)$, sleep disturbance $\left(r=-0.963^{* *}, p<0.0001^{* *}\right)$, Fatigue $\left(r=-0.972^{* *}, p<0.001^{* *}\right)$, WPI $\left(r=-0,953^{* *}, p<0.0001\right)$ and SS (r=$\left.0.901^{* *}, p<0.0001\right)$.

\section{CONCLUSIONS:}

In primary FMS patients melatonin level is lower than melatonin level in control, but MT level is high in secondary FMS patients. There was a negative correlation between MT with tender points, sleep disturbance, fatigue, SS \& WPI. But there was a positive correlation between MT \& cognitive symptoms.

\section{KEY WORDS:}

Fibromyalgia syndrome (FMS); Melatonin (MT); Widespread pain index (WPI) and symptom severity (SS) scale.

\section{Council for Innovative Research}

Peer Review Research Publishing System

\section{Journal: Journal of Advances in Chemistry}

Vol. 8, No. 3

editor@cirjac.com 


\section{INTRODUCTION:}

The key symptoms of fibromyalgia syndrome (FMS) are chronic, widespread pain associated with cognitive dysfunction, sleep disturbances and physical fatigue ${ }^{[8,24]}$. Also it is a clinical condition in which hyperalgesia, allodynia and stiffness of the body are found ${ }^{[17]}$.

Familial component, environmental factors, endocrinological and neurotransmitter changes, and psychological factors are suggested to contribute in the development of FMS ${ }^{[1]}$. Most patients with fibromyalgic syndrome (FMS) complain of sleep disturbances, fatigue, and pain. These symptoms might be a consequence of changed melatonin (MT) secretion, since MT is known to have sleep promoting properties.

Altered functioning of the hypothalamic-pituitary-adrenal axis and altered melatonin Production might modulate the circadian rhythm in patients with rheumatoid arthritis.

It has been reported that patients with this syndrome have a higher serum concentration of serotonin autoantibodies not only when compared with healthy controls ${ }^{[10]}$, but also when compared with patients with other rheumatic diseases ${ }^{[11]}$. Also low serum levels of both serotonin ${ }^{[23,26]}$ and its precursor tryptophan ${ }^{[20]}$ appear to prevail in patients with FMS.

Melatonin (MT) is a very popular neurohormone frequently investigated in recent years. MT was suggested to be effective in the etiology and treatment of some diseases. MT is synthesized primarily in the pineal gland ${ }^{\text {[22]. }}$

\section{OBJECTIVE:}

The aim of this study was to assess serum melatonin level \& investigate it's correlation to the clinical utility of fibromyalgia syndrome (FMS).

\section{PATIENTS AND METHODS:}

Fifty five patients, fulfilling the American Colleague of Rheumatology (ACR) criteria for FMS ${ }^{[24]}$ were selected from the in- and out-patients' clinics of the Rheumatology and Immunology department at Benha teaching Hospital. Twenty apparently healthy subjects of comparable age and sex to FMS patients were included as a control group.

All patients underwent full history taking and clinical examination including assessment of disease activity using the 2010 ACR FMS criteria ${ }^{[24]}$

A patient satisfies diagnostic criteria for fibromyalgia if the following 3 conditions are met:

1) Widespread pain index (WPI) $>7$ and symptom severity (SS) scale

score $>5$ or WPI 3-6 and SS scale score $>9$.

2) Symptoms have been present at a similar level for at least 3 months.

3) The patient does not have a disorder that would otherwise explain the pain.

\section{WIDESPREAD PAIN INDEX:}

1) WPI: note the number areas in which the patient has had pain over the last week. In how many areas has the patient had pain Score will be between 0 and 19 .

Shoulder girdle, left; hip (buttock, trochanter), left; jaw, left; upper back; shoulder girdle, right; hip (buttock, trochanter), right; jaw, right; lower back; upper arm, left; upper leg, left; chest; neck; upper arm, right; upper leg, right; abdomen; lower arm, left; lower leg, left; lower arm, right; lower leg, right.

\section{2) SS SCALE SCORE:}

I. Fatigue, Waking unrefreshed, Cognitive symptoms

For the each of the 3 symptoms above, indicate the level of severity over the past week using the following scale:

$\mathbf{0}=$ no problem

$\mathbf{1}=$ slight or mild problems, generally mild or intermittent

2 =moderate, considerable problems, often present and/or at a moderate level

$\mathbf{3}$ = severe: pervasive, continuous, life-disturbing problems

II. Considering somatic symptoms in general, indicate whether the patient has:*

0 = no symptoms

1 = few symptoms

$\mathbf{2}$ = a moderate number of symptoms

$\mathbf{3}=$ a great deal of symptoms

The SS scale score is the sum of the severity of the 3 symptoms (fatigue, waking unrefreshed, cognitive symptoms) plus the extent (severity) of somatic symptoms in general. The final score is between 0 and 12 . 
*Somatic symptoms that might be considered: muscle pain, irritable bowel syndrome, fatigue/tiredness, thinking or remembering problem, muscle weakness, headache, pain/cramps in the abdomen, numbness/tingling, dizziness, insomnia, depression etc...

Patients were divided into:

- Group I: Twenty five(25) patients with primary fibromyalgia diagnosed according to the 2010 ACR FMS criteria .

- Group II: Twenty five (30) patients with secondary fibromyalgia diagnosed according to the 2010 ACR FMS criteria .

- All patients subjected to the following investigations:

- Rheumatoid factor (RF),

-Anti nuclear antibodies (ANA)and anti-DNA antibodies by ELISA.

- Erythrocyte sedimentation rate (ESR) using the Westergren method .

- C-reactive protein (CRP).

\section{- MELATONIN DETERMINATION:}

Sera were collected from patients and controls and stored at $-20^{\circ} \mathrm{C}$ until use. Melatonin was quantitatively determined in the human serum by the enzyme linked immunosorbent assay (ELISA) supplied by Cusabio (Catalog No CSB-E08132h). An antibody specific to MT was bound to micro wells. Samples are then added to the micro wells with a biotin- conjugated antibody specific for Melatonin (MT) and avidin conjugated to Horseradish Peroxidase (HRP) is added to each micro wells and incubated. Then a TMB (3,3',5,5'tetramethyl-benzidine) substrate solution is added to each well. Only those wells that contain MT, biotin-conjugated antibody and enzyme-conjugated avidin will exhibit a change in color. The enzyme-substrate reaction is terminated by the addition of a sulphuric acid solution and the color change is measured spectrophotometrically at a wave lenght of $450 \mathrm{~nm} \pm 2 \mathrm{~nm}$. The concentration of melatonin is then determined in the samples.

\section{STATISTICAL ANALYSIS:}

Statistical analysis of the results were carried out using SPSS software statistical computer package version 14.0(SPSS Inc., IL), data expressed as Mean \pm SD or SEM Statistical differences between groups were determined by student's unpaired t-test. Significance was taken to be $p \leq 0.05$. Correlation coefficient $(\mathbf{r})$ was used for measuring the relationship between two variables.

\section{RESULTS:}

\section{Demographic data, clinical and laboratory features of FMS patients:}

This study included 55 FMS patients; all are females (100\%) and no males $(0 \%)$, their age ranged between 17-60 years ( $32.5 \pm 9.8$ years), disease duration ( $5.6 \pm 1.6$ years) and mean MT level of ( $32.5 \pm 13.9$ ).

Group I: included 25 patients with FMS, with a mean age of $33.2 \pm 13.8$ years, mean disease duration of $5.7 \pm 1.6$ years and mean MT level of $21.32 \pm 3.86$ (mean \pm SD).

Group II: included 30 FMS patients, with a mean age of $\mathbf{3 4 . 6} \pm \mathbf{1 3 . 1}$ years, a mean disease duration of $5.6 \pm 1.5$ years and mean MT level of $138.1 \pm 13.16$.

- The control Group Included 20 subjects, all are females with age of $\mathbf{3 6 . 2} \pm \mathbf{1 4 . 6}$ years. This group matched FMS patients as regards to age and sex, Table (1).

TABLE (1): Demographic data of FMS patients and controls

\begin{tabular}{|r|r|r|}
\hline Variable & \multicolumn{1}{|c|}{$\begin{array}{c}\text { FMS Patients } \\
(\mathbf{n = 5 5 )}\end{array}$} & $\begin{array}{c}\text { Controls } \\
(\mathbf{n}=\mathbf{2 0})\end{array}$ \\
\hline Age (years) & $32.5 \pm 13.9$ & $36.25 \pm 14.6$ \\
\hline Female: male & $55: 0$ & $20: 0$ \\
\hline
\end{tabular}




\section{MT level and Clinical features of FMS patients.}

In FMS patients, the titers of MT varied between 10.7 and $120.4 \mathrm{pg} / \mathrm{ml}$, with a mean of $86.5 \pm 8.01 \mathrm{pg} / \mathrm{ml}$.

- $\quad$ In the control group, the titers of MT varied between 18.8 and $41.4 \mathrm{pg} / \mathrm{ml}$, with a mean of $30.9 \pm 8.1 \mathrm{pg} / \mathrm{ml}$.

- There is a statistical significant difference was observed between MT level in FMS patients and the control group $(\mathrm{p}<0.011)$.

TABLE2: Comparison between MT level in healthy and FMS patients:

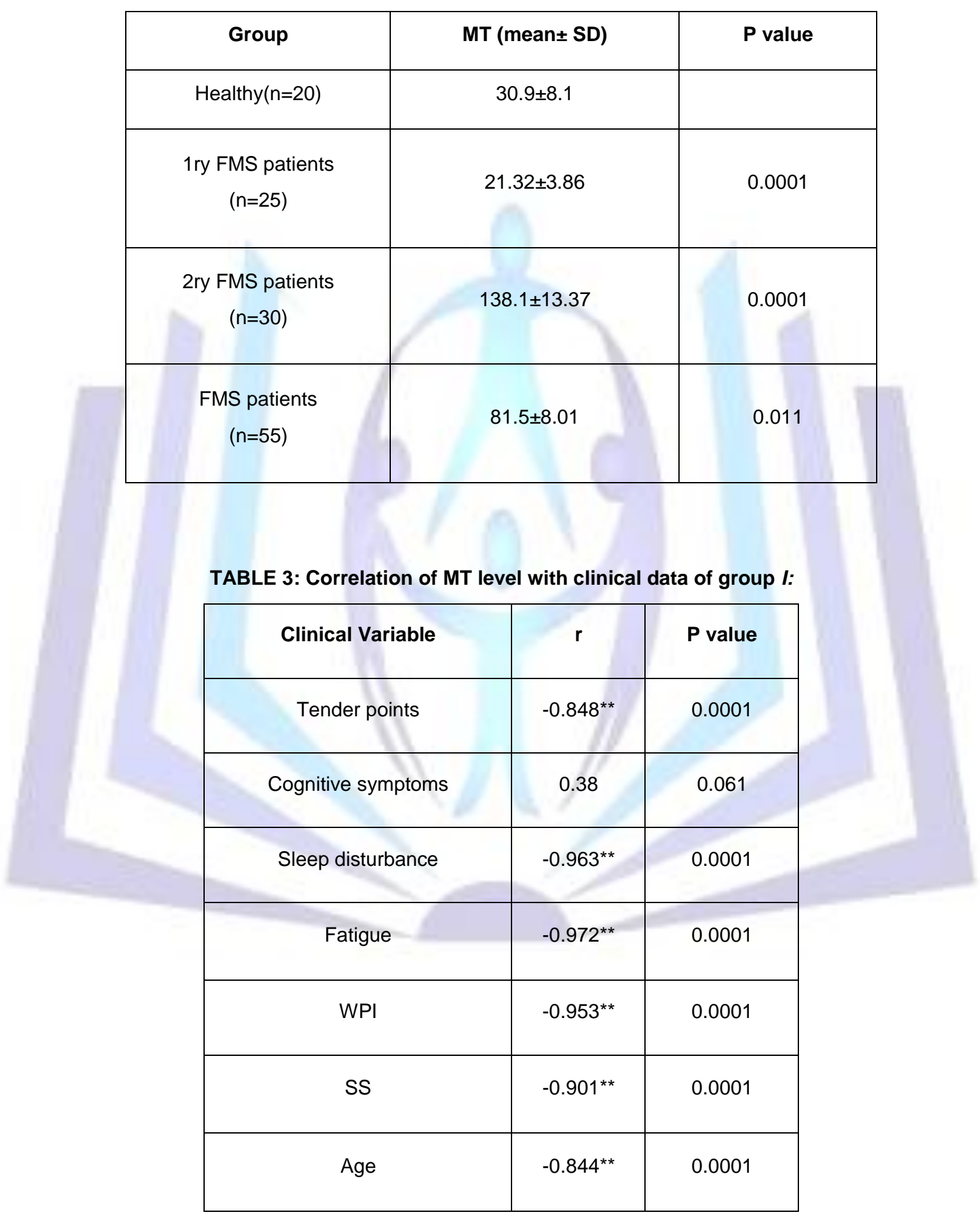

There were negative correlations of MT titers with tender points $\left(r=-0,848^{* *}, p<0.0001\right)$, sleep disturbance $(r=-$

$\left.0.963^{\star *}, \mathrm{p}<0.0001^{* *}\right)$, Fatigue $\left(r=-0.972^{* *}, \mathrm{p}<0.001^{\star *}\right)$, WPI $\left(r=-0.953^{* *}, \mathrm{p}<0.0001\right)$, Age $(r=-0.844, p<0.0001)$ and SS $(r=-$ $0.901^{* *}, p<0.0001$ ) (Figure 1). 

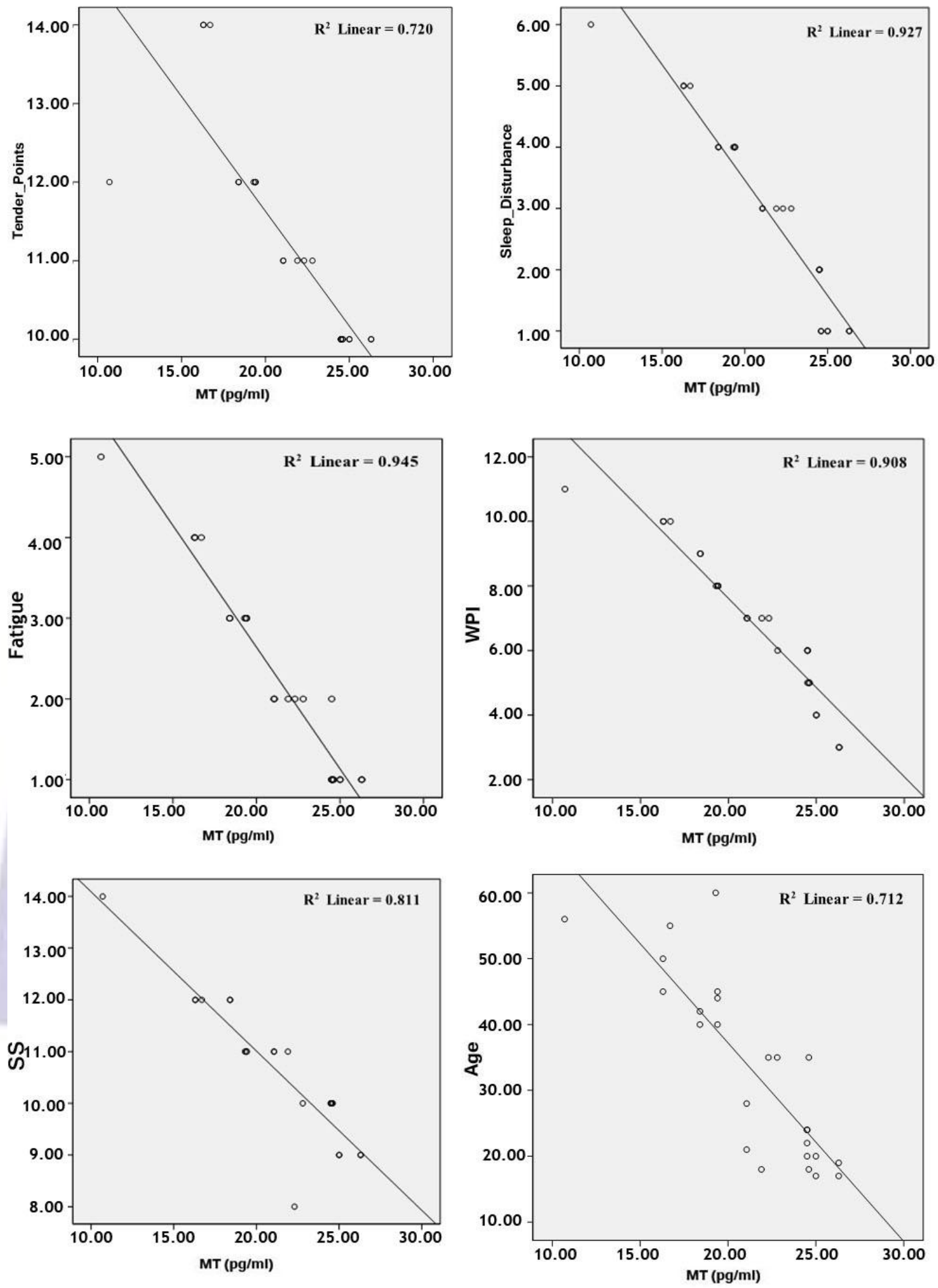

Figure(1): Correlation between MT with tender points, sleep disturbance, fatigue, SS, WPI and age in group I. 
TABLE 4: Correlation of MT level with clinical data of group II:

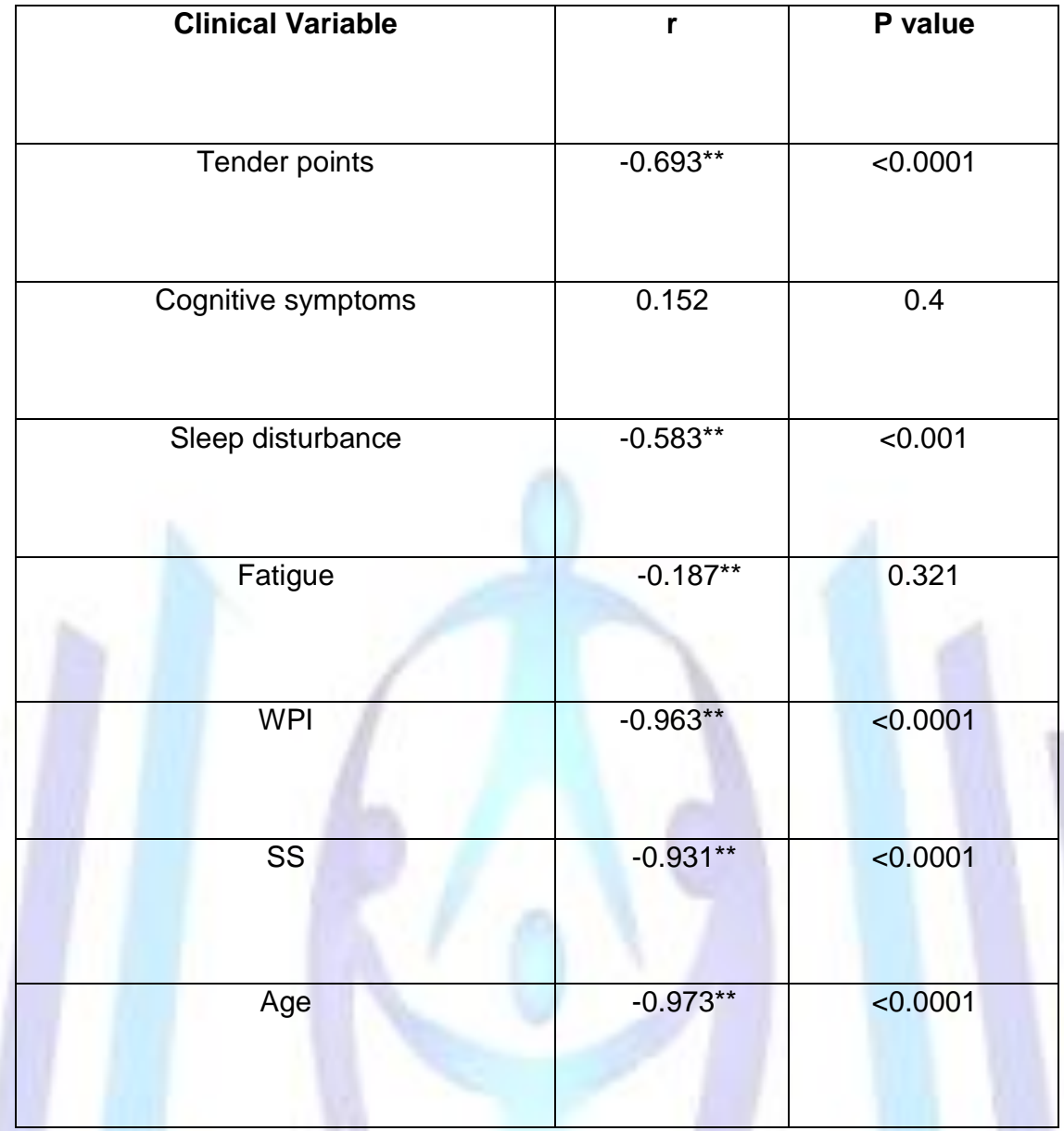

There were negative correlations of MT titers with tender points $\left(\boldsymbol{r}=-0,693^{* *}, p<0.0001\right)$, sleep disturbance $(\boldsymbol{r}=-$ $\left.0.583^{* *}, \mathrm{p}<0.001^{* \star}\right)$, Age $\left(r=-0.973^{* \star}, \mathrm{p}<0.0001^{* \star}\right)$, WPI $\left(r=-0.963^{* \star}, \mathrm{p}<0.0001\right)$ and SS $\left(r=-0.931^{* *}, \mathrm{p}<\right.$ $0.0001)$ ( Figure 2). 

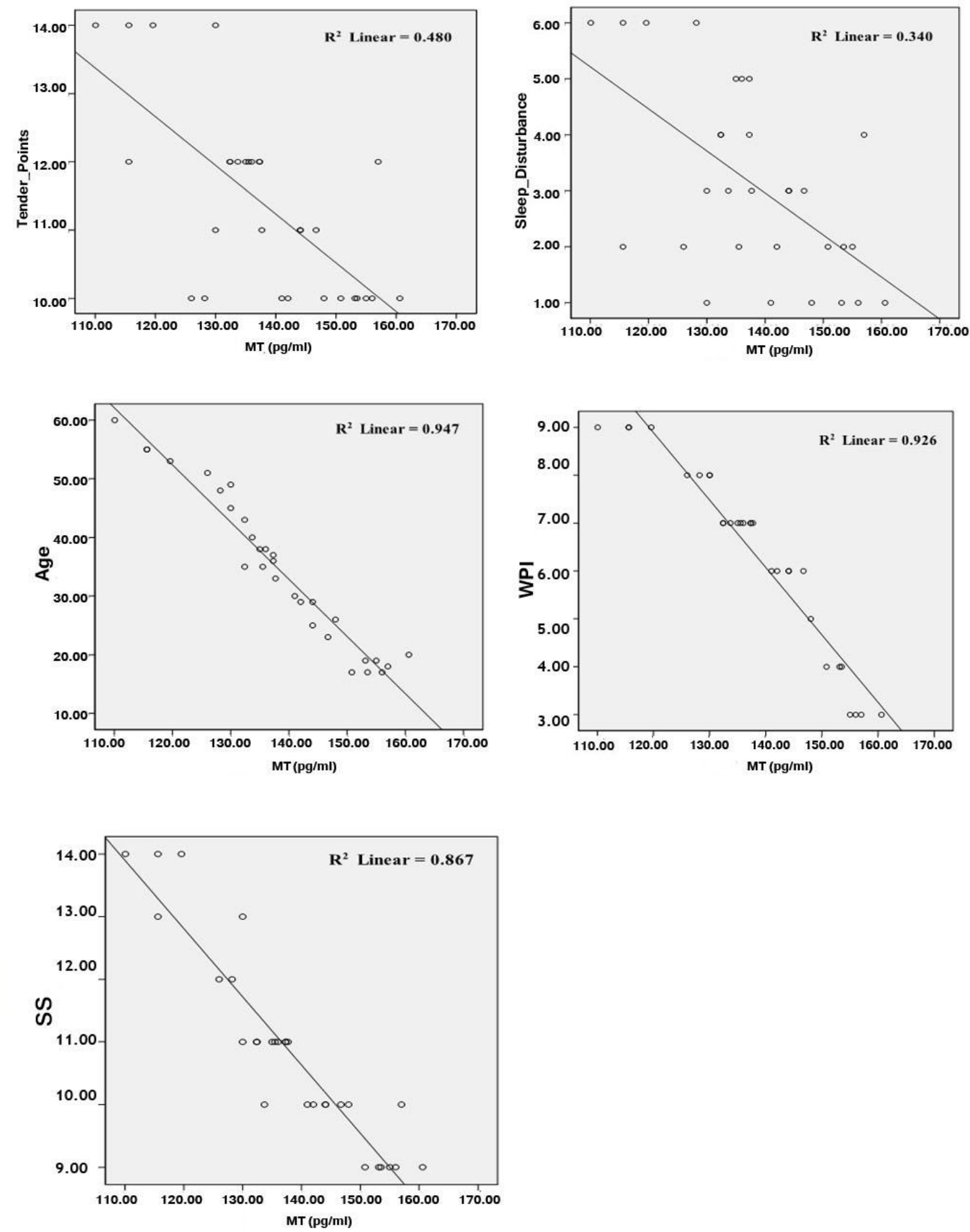

Figure(2): Correlation between MT with tender points, sleep disturbance, SS, WPI and age in group II. 
TABLE 5: Comparison between demographic data \&clinical data in healthy and FMS patients:

\begin{tabular}{|c|c|c|c|}
\hline Variable & $\begin{array}{c}\text { 1ry FMS } \\
\text { patients } \\
(n=25)\end{array}$ & $\begin{array}{c}\text { 2ry FMS } \\
\text { patients } \\
(n=25)\end{array}$ & value \\
\hline Tender points & $11.36 \pm 1.5$ & $\begin{array}{c}11.36 \pm \\
1.35\end{array}$ & 0.98 \\
\hline $\begin{array}{l}\text { Cognitive } \\
\text { symptoms }\end{array}$ & $3.8 \pm 0.46$ & $2.61 \pm 0.37$ & 0.48 \\
\hline $\begin{array}{c}\text { Sleep } \\
\text { disturbance }\end{array}$ & $2.9 \pm 0.3$ & $3.1 \pm 0.3$ & 0.750 \\
\hline Fatigue & $2.24 \pm 0.24$ & $3.0 \pm 0.37$ & 0.106 \\
\hline WPI & $6.08 \pm 0.44$ & $6.3 \pm 0.35$ & 0.33 \\
\hline SS & $7.36 \pm 0.28$ & $8.4 \pm 0.317$ & 0.018 \\
\hline $\begin{array}{c}\mathrm{MT} \\
\text { level }(\mathrm{pg} / \mathrm{ml})\end{array}$ & $21.32 \pm 3.8$ & $\begin{array}{l}138.1 \\
\pm 13.1\end{array}$ & 0.0001 \\
\hline Age(years) & $33.2 \pm 13.8$ & $34.6 \pm 13.1$ & \\
\hline $\begin{array}{l}\text { Disease } \\
\text { duration } \\
\text { (years ) }\end{array}$ & $5.7 \pm 1.6$ & $5.6 \pm 1.5$ & \\
\hline
\end{tabular}

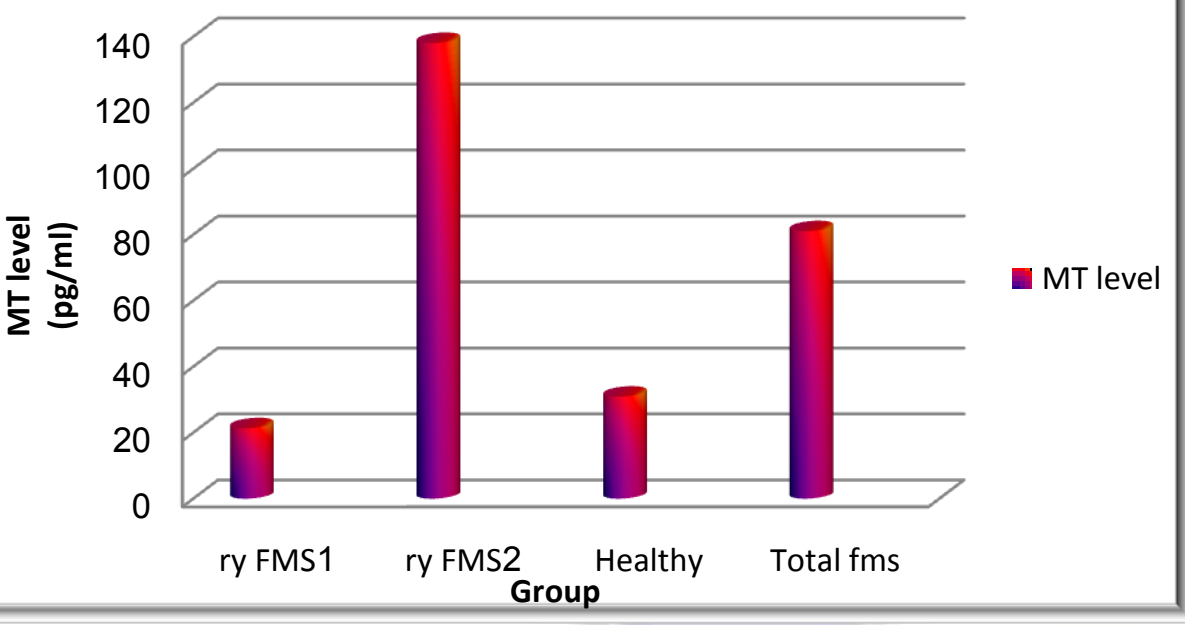

1ry FMS: primary fibromyalgia patients.

2ry FMS: secondary fibromyalgia patients.

Total FMS: total fibromyalgia patients. 


\section{DISCUSSION:}

Fibromyalgia is a common rheumatologic disorder that is under diagnosed. Using the 1990 ACR classification criteria, the prevalence of fibromyalgia in the general population is reported to be higher than in women than men ${ }^{[20]}$.

There is a higher prevalence in females because females produce more neurotransmitters that increase pain signals and fewer neurotransmitters that decrease pain signals than males, so in our study we observe that all patients are females ${ }^{[15]}$.

Studies suggested that when endogenous tryptophan is depleted, there is a dramatic drop in the synthesis of serotonin in females ${ }^{[19]}$, this make females being more sensitive to pain ${ }^{[26]}$.

The syndrome may coexist with other rheumatic diseases such as rheumatoid arthritis and systemic lupus erthymatosus in this case fibromyalgia be considered a secondary type ${ }^{[2]}$.

Disturbances in melatonin secretion have been proposed to be part of the pathophysiology leading to FMS

The circadian rhythm ${ }^{[12]}$ and secretion of melatonin have been examined in patients with FMS ${ }^{[13]}$. No significant differences were observed in the 24-hr plasma melatonin, between ten subjects and ten controls ${ }^{[12]}$.

We found that MT level was lower in primary FMS patients compared with healthy age and sex-matched subjects. The clinical implication of this finding is disturbed sleep at night and, as consequence, daytime sleepiness, fatigue and increased pain. Sleep disturbances, fatigue and cognitive dysfunction, are symptoms present in almost patient with FMS $[8,16]$, including those in this study.

In our study, MT levels of FMS patients were found to be lower than control group. There was correlation between the MT levels and pain, fatigue, and sleeping disorders. Our results weren't agree with the study of Press et al, Senel et al\& Klerman ${ }^{[12,19,21]}$.

In concordance to the work included an eight patients with FM and eight controls, the concentration of melatonin in plasma and urine was found to be significantly lower in patients with FM ${ }^{[23]}$ this agree with our data. But, Korszun et al. ${ }^{13]}$ however, reported that the melatonin concentration in urine was elevated in patients with FM when compared to controls.

Our data imposed that, in 1ry FMS there were negative correlations of MT titers with tender points ( $\boldsymbol{r}=-$ $\left.0.848^{\star *}, \mathrm{p}<0.0001\right)$, sleep disturbance $\left(r=-0.963^{\star *}, \mathrm{p}<0.001^{\star \star}\right)$, Fatigue $\left(\boldsymbol{r}=-0.972^{\star \star}, \mathrm{p}<0.001^{\star \star}\right)$, WPI $\left(\boldsymbol{r}=-0.953^{\star \star}\right.$, $\mathrm{p}<0.0001)$ and SS $\left(r=-0.901^{* *}, p<0.0001\right)$.

Some authors had reported that patients with depression have decreased secretion of MT and increased secretion of cortisol $^{[3]}$. As most FMS patients show signs of depression, a decreased MT level may explain their symptoms.

Decreased MT synthesis may be brought about by impaired provision of tryptophan. The amino acid tryptophan transforms into serotonin in the pineal gland, which then transforms into MT hormone. The decrease in serotonin as a result of the decrease in the absorption of tryptophan in FMS patients was suggested to be responsible for the decrease in MT synthesis, and accordingly that this may result in the abnormal sleeping pattern and typical FMS pain ${ }^{[9]}$.

For patients with rheumatoid arthritis (RA), social disadvantage, psychological distress and RA severity predicted future development of FMS ${ }^{[3]}$.

Many studies ${ }^{[5]}$ confirmed that melatonin levels are increased in rheumatoid patients compared with sex and age matched healthy controls. Melatonin has been reported to stimulate the production of IL6 and Th1 related proinflammatory cytokines such as IL12, IL1\&IL2, which are involved in the pathophysiology of rheumatoid arthritis ${ }^{[6]}$.

Melatonin is synthesized in human bone marrow cells ${ }^{[4]}$ However, it has been found to be present at a rather high concentration in synovial fluid from rheumatoid patients, and recently it has been reported that synovial macrophages from rheumatoid patients have specific binding sites for melatonin ${ }^{[14]}$.

The levels of plasma melatonin were highest in SLE patients Plasma melatonin levels did not correlate with measures of clinical disease activity ${ }^{[7]}$.

In this current study melatonin level was high in 2ry FMS patients, who are having RA \& SLE associated with FMS compared with healthy age and sex-matched subjects. This agree with the studies that observed that MT levels are higher in RA \& SLE patients ${ }^{[5]}$.

Also in this study there is a correlation between MT level and clinical features of 2ry FMS such as sleep disturbance, fatigue \& more.

In our results about 2ry FMS there were negative correlations of MT titers with tender points $\left(r=-0.693^{\star *}, p<0.0001\right)$, sleep disturbance $\left(r=-0.583^{\star *}, p<0.001^{\star *}\right)$, Age $\left(r=-0.973^{\star *}, p<0.001^{* \star}\right)$, WPI $\left(r=-0.963^{* *}, p<0.0001\right)$ and SS $\left(r=-0.931^{\star *}\right.$, $\mathrm{p}<0.0001)$.

Melatonin level didn't seem to play a role in secondary fibromyalgia (patients with FMS associated with other diseases such as RA, SLE) which may be included by other factors which should be investigated in the future. 


\section{IN CONCLUSION:}

Our study indicated that FMS associated with sleep disturbance, fatigue \& cognitive dysfunction. Low MT level in primary fibromyalgia patients \& high MT level in secondary fibromyalgia patients was observed. There was a negative correlation between MT with tender points, sleep disturbance, fatigue, SS \& WPI.

\section{RECOMMENDATIONS:}

* Further study on MT level in primary \& secondary fibromyalgia patients.

* Further investigation on cytokines and it's relation to melatonin in patients with FMS.

* New researches about correlation between MT with symptoms of FMS.

* Other studies on the effect of exogenous MT on FMS patients.

* Other studies on MT in 2ry patients (FMS with RA, SLE and other connective tissue) and it's relation to disease activity.

Corresponding author is Shimaa sabry
* Mobile:01065694851
* E-mail: shimaasabry862 @ Yahoo.com

\section{REFERENCES:}

1. Acuna-Castroviejo D, Escames G, Reiter RJ (2006): Melatonin therapy in fibromyalgia. J Pineal Res 40(1):98-99.

2. Baumgartner E, Finckh A, Cedraschi C, Vischer TL (2002): A six-year prospective study of a cohort of patients with fibromyalgia. Ann Rheum Dis; 61:644-645.

3. Beck-Friis, J., Kjellman, B.F. \& Wetterberg, L. (1985): Serum melatonin in relation to clinical variables in patients with major depressive disorder and a hypothesis of a low melatonin syndrome. Acta Psychiatry Scandinavia, 71, 319-330.

4. Conti A, Conconi S, Hertens E, Skwarlo-Sonta K, Markowska M, Maestroni G.(2000): Evidence for MLT synthesis in mouse and human bone marrow cells. J Pineal Res;28:193-202.

5. Cutolo M, M Maestroni G J, Otsa K, Aakre O, et al., (2005):Circadian melatonin and cortisol levels in rheumatoid arthritis patients in winter time: a north and south Europe comparison Ann Rheum Dis;64:212-216.

6. Firestein GS(2003): Evolving concepts of rheumatoid arthritis. Nature; 423:356-61.

7.Haga H J, Brun J G, Rekvig O P (1999): Seasonal variations in activity of systemic lupus erythematosus in a subarctic region, lupus vol. 8 no. 4 269-273.

8. HäuserW, Zimmer C, Felde E, Köllner V(2008): What are the key symptoms of fibromyalgia? Results of a survey of theGerman Fibromyalgia Association [Was sind die Kernsymptome des Fibromyalgiesyndroms? Umfrageergebnisse der Deutschen Fibromyalgievereinigung.]. Schmerz;22(2):176-83.

9. Khaldy H, Leo'n J, Escames G, Bikjdaouene L, Garcı'a JJ, Acuna Castroviejo D (2002): Circadian rhythms of dopamine and dihydroxyphenyl acetic acid in the mouse striatum: effects of pinealectomy and of melatonin treatment. Neuroendocrinology75(3):201-208.

10. Klein, R. \& Berg, P.A. (1994): A comparative study on antibodies to nucleoli and 5-hydroxytryptamine in patients with fibromyalgia syndrome and tryptophan-induced eosinophilia-myalgia syndrome. Clinical Investigator, 72(7), 541-549.

11. Klein, R., Bansch, M. \& Berg, P.A. (1992): Clinical relevance of antibodies against serotonin and gangliosides in patients with primary fibromyalgia syndrome. Psychoneuroendocrinology, 17(6), 593-598.

12. Klerman EB, Goldenberg DL, Brown EN, Maliszewski AM, Adler GK (2001): Circadian rhythms of women with fibromyalgia. J Clin Endocrinol Metab ; 86:1034-1039.

13. Korszun A, Sackett-Lundeen L, Papadopoulos E et al(1999): Melatonin levels in women with fibromyalgia and chronic fatigue syndrome. J Rheumatol; 26:2675-2680.

14. Maestroni G, Sulli A, Pizzorni C, Villaggio B, Cutolo M.(2002): MLT in rheumatoid arthritis: a disease promoting and modulating hormone? Clin Exp Rheumatol;20:872-3.

15. Mease P. Fibromyalgia syndrome(2005): review of clinical presentation, pathogenesis, outcome measures, and treatment. J Rheumatol Suppl 2005; 75:6-21.

16. Moldofsky, H. (1982): Rheumatic pain modulation syndromes: The interrelationships between sleep, central nervous system, serotonin and pain. Advances in Neurology, 33, 51-57.

17. Neumann L, Buskila D(2003): Epidemiology of fibromyalgia. Cur. Pain Headache Rep.;7:362-368. 
18. Nishizawa S, Benkelfat C, et al(1997): Differences between males and females in rates of serotonin synthesis in human brain. Proc National Acad Sci USA 94:530813.

19. Press J, Phillip M, Neumann L, Barak R, Segev Y, Abu-Shakra M, Buskila D (1998): Normal melatonin levels in patients with fibromyalgia syndrome. J Rheumatol 25(3):551-555.

20. Reiter RJ, Acuna-Castroviejo D, Tan DX(2007): Melatonin therapy in fibromyalgia. Curr Pain Headache Rep 2007; 11:339-342.

21. Senel K, Baykal T, Melikoglu MA, Erdal A, Karatay S, Karakoc A, Ugur M (2011): Serum melatonin levels in ankylosing spondylitis: correlation with disease activity. Rheumatol Int 31(1):61-63.

22. Stratz, T., Samborski, W., Hrycaj, P., Pap, T., Mackiewicz, S., Mennet, P. \& Muller, W. (1993): Serotonin concentration in serum of patients with generalized tendomyopathy (fibromyalgia) and chronic poly- arthritis. Medizinische Klinik, 88(8), 458-462.

23. Wikner J, Hirsch U, Wetterberg L, Rojdmark S(1998): Fibromyalgia - a syndrome associated with decreased nocturnal melatonin secretion. Clin Endocrinol (Oxf) ; 49:179-183.

24 . Wolfe F, Clauw DJ, Fitzcharles MA, Goldenberg DL, Katz RS, Mease P, et al(2010): The American College of Rheumatology preliminary diagnostic criteria for fibromyalgia and measurement of symptom severity. Arthritis and Rheumatism;62(5):600-10.

25. Wolfe F, Ross K, Anderson J, Russell IJ, Hebert L (1995): The prevalence and characteristics of fibromyalgia in the general population. Arthritis Rheum; 38:19-28.

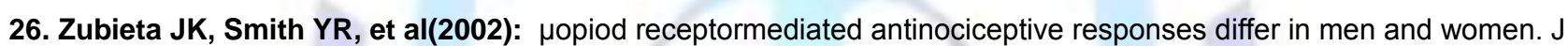
Neurosci 22(12):100-107 